\title{
Elementos Visuais e Simbólicos das Etiquetas Têxteis: A Interação do Usuário
}

\author{
Visual and Symbolic Elements of Textile Labels: User Interaction
}

TURCATTO, S. Andressa; Mestranda em Design de Vestuário e Moda; Universidade do Estado de Santa Catarina - UDESC

andressa.turcatto@hotmail.com

SILVEIRA, Icléia; Doutora; Universidade do Estado de Santa Catarina - UDESC

icleiasilveira@gmail.com

\section{Resumo}

As etiquetas têxteis são interfaces comunicacionais, com as quais os usuários interagem, diariamente, na sua relação com o vestuário. Existem diferentes tipos de etiquetas para exercer funções distintas, e, cada uma delas é composta por elementos gráficos que informam o consumidor consoante suas especificidades. Este estudo, portanto, irá abordar os diferentes tipos de materiais empregados na confecção das etiquetas para o vestuário, as principais tendências para o setor e possibilidades de inovação para a melhoria do desempenho dessas interfaces. Quanto aos procedimentos metodológicos a pesquisa é descritiva de natureza qualitativa. Como resultado, o levantamento dos materiais mais comumente utilizados no mercado de etiquetas têxteis, tema pouco explorado por pesquisas na moda e no design, bem como apontamentos que convergem para o aperfeiçoamento dessas interfaces.

Palavras Chave: etiquetas têxteis; interfaces comunicacionais; interação usuário.

\begin{abstract}
Textile labels are communicational interfaces, which interact with users on a daily basis in their relationship with clothing. There are different types of labels to perform different functions and each is composed of graphical elements that inform the consumer about their specifics. This study will address the different types of materials used in the manufacture of clothing labels, the main trends for the industry and possibilities for innovation to improve the performance of these interfaces. As for methodological procedures, the research is descriptive of a qualitative nature. As a result the survey of the most commonly used materials in the market of textile labels, theme little explored by fashion research and design, as well as notes that converge to the improvement of these interfaces.
\end{abstract}

Keywords: textile labels; communication interfaces; user interaction. 


\section{Introdução}

As etiquetas têxteis nem sempre estiveram presentes em nossa relação de consumo com o vestuário. Estas surgem no século XIX, pelas mãos de Charles Worth, creditado como fundador da indústria moderna da alta costura, imprimindo o papel do estilista como criador de tendências (MACKENZIE, 2010).

A partir de Worth e, junto dele, os grandes estilistas da época começaram a "assinar" suas coleções, assim como os artistas o faziam, inserindo uma etiqueta em suas peças, ou obras de arte, como preferiam acreditar (SVENDSEN, 2010). Essas etiquetas reforçavam a ideia de originalidade de suas criações, elevando seus nomes a admiração, estando sempre presentes em suas peças.

Já no século $X X$, com a chegada do tecido sintético a identificação pelos materiais nobres utilizados na confecção das roupas confundia o consumidor, ávido pelas peças mais luxuosas fabricadas pelos melhores estilistas. A solução foi deslocar as etiquetas afixadas dentro das peças para seu exterior enaltecendo a identidade de quem a havia criado. Todos os artigos do vestuário eram marcados pelos nomes, monogramas ou logomarcas de seus fabricantes. O preço, deixou muitas vezes, de estar atrelado ao custo do material ou sua dificuldade de confecção para estar em uma instância simbólica de valor (LURIE, 1997).

Desde então, as etiquetas mudaram em grande parte pelo material, pela grafia, pelos símbolos apresentados e, também, pelo tipo de informação transmitida. Veja-se, por exemplo, as etiquetas de conservação e manutenção têxtil, extremamente importantes para o cuidado adequado dos produtos, mas antes inexistentes. Entretanto, a sua função de comunicar informações - seja de conservação, seja do fabricante - a respeito dos artigos têxteis, mantêm-se perene.

Quer dizer: as etiquetas e tags são interfaces comunicacionais responsáveis pela transmissão de informações. São por assim dizer, suporte para diversas mensagens. O que evidencia a importância da escolha de todos os aspectos que darão personalidade as etiquetas.

Nesse sentido, o trabalho do designer gráfico está, justamente, em manipular os elementos visuais em função de comunicar uma mensagem visual. Todo o designer cria ou projeta imagens. Faz parte do seu papel como comunicador visual. E nesse processo, alguns elementos visuais se evidenciam em função da mensagem pretendida. Seja pela utilização de determinada cor na composição imagética dos elementos, como pela escolha do material a ser impresso. As etiquetas e tags são interfaces comunicacionais responsáveis pela transmissão de informações e suporte para diversas mensagens. Evidenciando assim, a importância da escolha de todos os aspectos que darão personalidade as etiquetas.

Com isso, iremos abordar nesta investigação, os tipos de etiquetas presentes nas peças do vestuário, além do tipo de interação que estabelecem com os usuários e suas mensagens intrínsecas. Os materiais dos quais elas são confeccionadas, gerando discussões a respeito de fatores de usabilidade na projeção dessas interfaces. Assim como, apresentando novos materiais e tendências a serem explorados pelos designers diante do desenvolvimento desses artigos, propondo novos indicadores de interação pelo usuário e consumidor.

Debruçar-se sobre este tema amplia o envolvimento do designer com questões de usabilidade e a criação de interfaces que se comuniquem mais efetivamente com seu público por 
meio de decisões gráficas mais acertadas, gerando mais valor ao produto do qual aquela etiqueta faz parte. Além de que, por uma pesquisa preliminar, constatou-se a divulgação insipiente do universo das etiquetas, interfaces importantes na relação do consumidor com o vestuário.

Quanto aos procedimentos metodológicos a pesquisa é descritiva de natureza qualitativa, pela qual busca através da narração das especificidades das etiquetas têxteis provocar discussões a respeito da interação entre interface-usuário, bem como conduzir a novas perspectivas na elaboração das etiquetas, em especial na decisão pelos materiais.

Iniciamos o estudo compreendendo os diferentes tipos de etiquetas e tags atreladas ao vestuário e seus elementos gráficos.

\section{Etiquetas Têxteis: elementos gráficos e categorização}

A etiqueta é parte essencial na elaboração e comercialização das peças do vestuário. O seu principal objetivo está em facilitar a leitura dos usuários e instruí-los quanto as informações referentes aos produtos. As etiquetas devem manter-se intactas durante toda a vida útil dos produtos, o que muitas vezes não acontece por questões, principalmente, de conforto, pois muitos usuários destacam suas etiquetas das peças de vestuário.

É por meio desta interface e de seus elementos gráficos que as marcas comunicam suas intenções aos consumidores. Não mais como no passado, onde as etiquetas mostravam apenas quem as produzia ou ainda, para evidenciar a exclusividade de seus compradores, hoje elas falam dos próprios consumidores, do seu comportamento e do contexto cultural em que estão inseridos (SIROTTI, 2000). Isto, pois com o tempo, novas relações foram estabelecidas entre o usuário consumidor - e a interface.

Além das diferenças de informações técnicas e específicas de cada etiqueta ou tag, há também diferenças quanto ao layout dessas interfaces. A escolha por determinada configuração é gerenciada pelo designer gráfico no processo de criação desses artigos. As etiquetas técnicas, que contém informações essenciais ao cuidado com as peças do vestuário, sua origem e composição têxtil geralmente não sofrem grandes alterações entre marcas distintas, já que são as únicas normatizadas no Brasil. Entretanto, o fator mais variante é o tipo de impressão e o material de confecção.

Por outro lado, a tag é um artigo que sofre grandes mudanças entre marcas e produtos. Cada marca a usa como artificio para diferentes fins. O principal é a apresentação da identidade da marca, através da logo ou ainda uma pequena descrição do seu posicionamento em forma de tagline, ou ainda informações mais específicas sobre o produto em si.

Como não há uma sistematização ou padronização das etiquetas ao que compreende os aspectos de composição como informações de referência, - exceto as etiquetas de conservação e manutenção do vestuário - posição de fixação ou material de confecção, iremos utilizar a terminologia utilizada por Schneider (2016) para determinar os tipos de etiquetas mais presentes no mercado, a saber: a) etiquetas técnicas; b) etiquetas institucionais; c) etiquetas promocionais; e d) etiquetas comerciais.

A categorização de cada tipo de interface nos levará a perceber seus padrões de informações, bem como o tipo de interação que cada uma delas estabelece com o usuário. 


\subsection{Etiquetas de conservação e manutenção ou etiquetas técnicas}

As etiquetas de conservação ou manutenção do vestuário ou etiquetas técnicas são as únicas que obedecem a normas preestabelecidas, como já mencionamos. Elas são normatizadas pelo Conselho Nacional de Metrologia, Normalização e Qualidade Industrial (CONMETRO) que determina os itens a serem informados nas etiquetas (são eles: razão social; CNPJ do fabricante; país de origem; composição das fibras que compõem os produtos têxteis; tamanho da peça e cuidados de conservação) e ainda fiscalizadas pelo Instituto Nacional de Metrologia, Qualidade e Tecnologia (INMETRO). O que confere às empresas a responsabilidade de cumprir as determinações dos referidos órgãos, comunicando com eficiência as informações dos produtos têxteis ao consumidor.

Ainda em relação as informações técnicas presentes nas etiquetas de conservação e manutenção, a norma da ABNT NBR NM ISSO 3758 estabeleceu um sistema de símbolos gráficos para o uso de artigos têxteis, fornecendo informações a respeito da conservação de peças do vestuário com o objetivo de prevenir danos aos artigos têxteis durante os processos de manutenção. A condensação dessas informações em símbolos visa informar de maneira mais objetiva e reduzida para que comporte o espaço dedicado a elas na etiqueta e facilitar a compreensão do consumidor. Esses símbolos seguem padrões internacionais, sendo compreendidos em várias partes do mundo pela mesma configuração gráfica e com o respectivo entendimento sobre o conteúdo.

Os símbolos gráficos apresentam vantagens na interpretação de seus códigos em relação as mensagens escritas. Faz parte do processamento e memorização rápidos gerados pela ação das imagens em detrimento da linguagem escrita. Na Figura 1, apresentamos um modelo de etiqueta técnica.

Figura 1 - Etiqueta técnica.

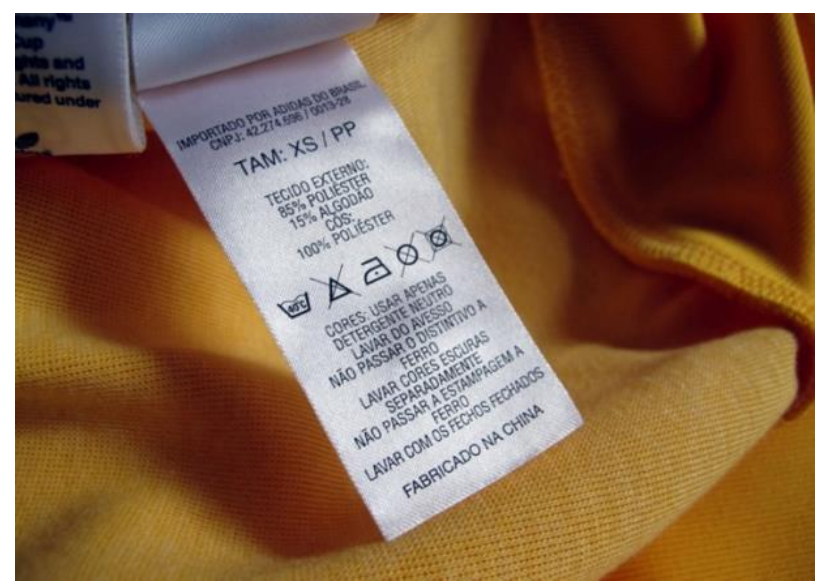

Fonte: gazetadopovo.com.br (2013)

Há que se destacar, no entanto, que a interação dos usuários com as etiquetas técnicas passa por algumas barreiras no entendimento de seus símbolos, uma vez que o significado dos símbolos de conservação e manutenção do vestuário são pouco compreendidos pela maioria da população, fazendo com que o usuário aja por intuição quando não entende seu conteúdo. Ação que pode acarretar sérios danos ao produto se as informações forem interpretadas de maneira 
errônea. Justamente por isso, alguns fabricantes anexam informações que descrevem as características de cada símbolo para garantir a compreensão efetiva do que significam.

\subsection{Etiquetas institucionais}

Conforme já afirmamos, as etiquetas institucionais foram as primeiras etiquetas a serem produzidas para o vestuário. Seu principal objetivo é apresentar e transmitir a identidade da marca por meio de uma logomarca ou monograma fixados internamente ou externamente. Nessas etiquetas podem ser aplicados uma infinidade de características têxteis, de cores, texturas e de layout (SCHNEIDER, 2016). Como, também, já mencionamos, a etiqueta institucional se relaciona de maneira muito emocional com os consumidores, por que a ela estão atrelados símbolos de identificação com a marca do produto. Na Figura 2, a exemplificação de uma etiqueta institucional.

Figura 2 - Etiqueta institucional.

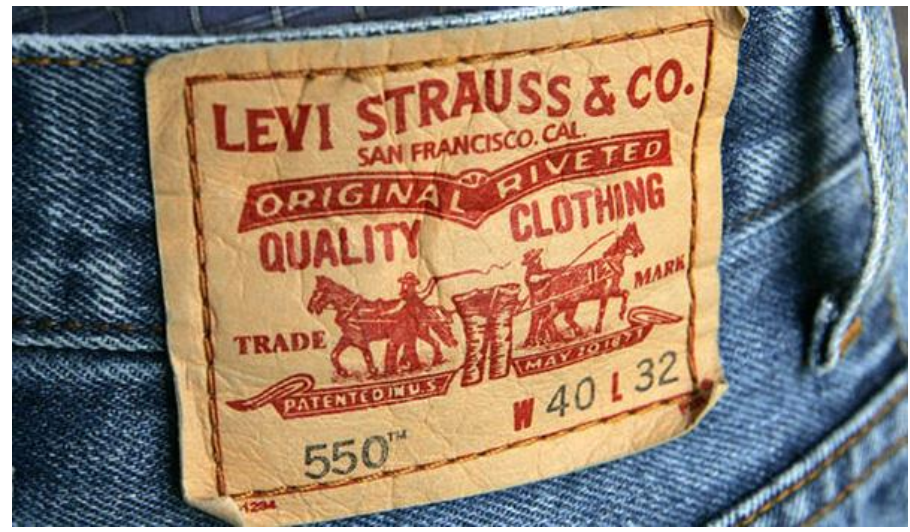

Fonte: coolmaterial.com (2018)

A relação dos consumidores com as etiquetas institucionais demarca o caráter simbólico atrelado ao vestuário. A exibição de uma logomarca diz muito sobre a personalidade de quem as veste, e, desta forma, agrega ao indivíduo pequenos flashes de sua personalidade caracterizados pela escolha diária do vestuário. Desta forma, a criação desse tipo de etiqueta possui papel relevante na construção do produto como um todo.

\subsection{Etiqueta promocional ou tag}

A etiqueta promocional ou tag são artigos de grande variância entre as marcas e se mostram, também, como interfaces importantes na comunicação dos valores simbólicos da marca. Na maioria das vezes, estas interfaces estão presentes somente no momento da compra, sendo descartada quando do uso do produto pelo usuário.

Em alguns casos podemos encontrar informações técnicas no verso da tag, com o objetivo de, no momento da escolha das peças, facilitar o entendimento do consumidor por esses itens de maneira mais ágil. $\mathrm{O}$ tipo de layout, cor, textura ou padronagem, também, assim como a etiqueta institucional, estão intrinsicamente ligados a linguagem visual proposta pela marca (SCHNEIDER, 2016). A Figura 3 trás um desses artigos. 
Figura 3 - Etiqueta promocional ou tag.
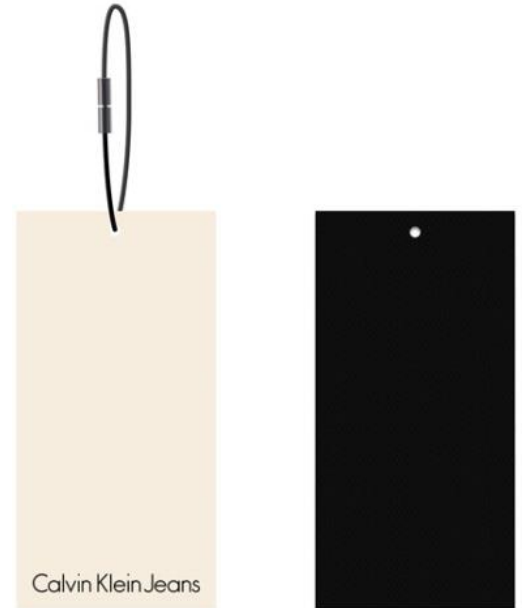

Fonte: studio191ny.com (2013)

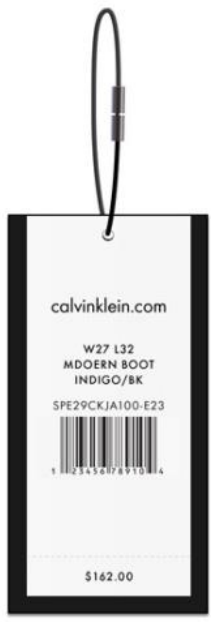

A brevidade da funcionalidade da tag nos faz pensar a respeito de novas possibilidades para a interface. Será possível mantê-la após a escolha da peça, atribuindo-lhe novos sentidos? Provocação, esta, lançada para os designers no desenvolvimento de novas composições de interfaces para o vestuário. Um exemplo de ressignificação das tags já foi proposto pela empresa catarinense Tecnoblu, que desenvolve artigos de identificação para o vestuário. Na proposta da aludida empresa, as tags se transformaram em acessórios e brindes para os clientes, como porta óculos ou marca livros. A ideia surgiu quando um de seus clientes encomendaram bolsas em formato de tags, mudando totalmente o sentido para que elas foram criadas (MANTHEY, 2014).

\subsection{Etiquetas comerciais}

Completando a categorização das principais etiquetas presentes no mercado, temos, ainda, as etiquetas comerciais, nas quais, informações básicas relativas a compra do artigo têxtil são apresentadas, como preço, tamanho e códigos de rastreamento na loja. Essas etiquetas estão presentes somente no momento da compra, tendo a sua interação resumida a decisão pelo produto. E, geralmente, são confeccionadas em material plástico. A Figura 4 mostra um exemplo de etiqueta comercial. 
Figura 4 - Etiqueta comercial.

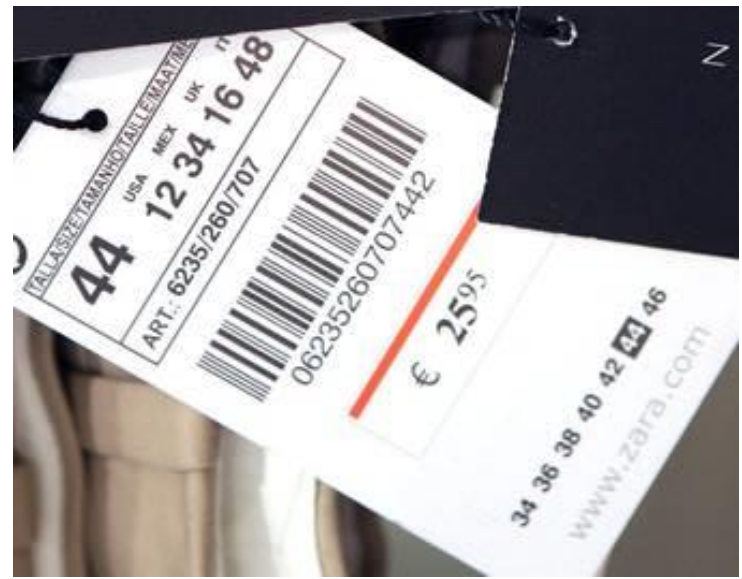

Fonte: oglobo.globo.com (2014)

Agora que já categorizamos os diferentes tipos de etiquetas, bem como identificamos os principais aspectos de interação estabelecidos por cada uma delas, passamos a descrever os principais materiais utilizados em sua confecção e reflexões a respeito da usabilidade desses artigos.

\section{Materiais das etiquetas e tags}

A escolha pelos materiais das etiquetas e tags é um dos componentes mais importantes na construção desses artigos. A maioria dessas interfaces está em contato direto com o corpo e, muitas vezes, geram desconforto durante o uso em função de seu material, fazendo com que muitos usuários destaquem suas etiquetas das peças de vestuário. O maior malefício desse hábito é a perca de informações essenciais a respeito do produto, como os símbolos de manutenção, inseridos nas etiquetas técnicas, importantes no cuidado com as peças do vestuário.

A usabilidade, nas etiquetas de roupas, pode ser abordada segundo dois referenciais. $O$ primeiro diz respeito a eficácia na apresentação das informações aos usuários; e o segundo, diz respeito a maneira com que são fixadas no vestuário. A adequação destes dois referenciais é capaz de minimizar o desconforto, promovendo uma maior satisfação no uso (GARCIA et al, 2012).

Todas as informações inseridas nas etiquetas precisam ser apresentadas de forma clara para que se comuniquem com eficácia com o usuário, nesse sentido, a usabilidade também se relaciona com interfaces e produtos em razão da construção de seus elementos gráficos e imagéticos.

Outra questão que abrange a usabilidade, são as relações de conforto entre interfaceusuário ou produto-usuário. Nas etiquetas isso fica evidente pela posição afixada nas peças e pelo material utilizado em sua fabricação. Os resultados da pesquisa de Garcia et al, apontam que a grande maioria das pessoas sentem desconforto ao vestir peças com etiquetas, em pelo menos alguma experiência de uso. Cerca de $87 \%$ dos usuários entrevistados assinalam essa resposta.

Desta forma, fica evidente a importância de adequação do material ao tipo de etiqueta para que exerça a sua função com a maior eficiência possível, para que, preserve o conforto no 
uso diário e as informações sejam identificadas com clareza enquanto o produto estiver sendo utilizado pelo usuário. A seguir identificamos os materiais mais comumente utilizados na fabricação dos diferentes tipos de etiquetas.

\subsection{Etiquetas técnicas}

O material mais utilizado na confecção de etiquetas de conservação e manutenção têxtil é o nylon. Esse substrato apresenta um custo benefício baixo para a produção em grandes quantidades, o que atrai em grande parte as marcas, mas por ser um material sintético causa desconforto quando em contato com o corpo. Não por outro motivo estas são as principais etiquetas a serem removidas pelos usuários. Outra desvantagem desse material, é a facilidade com que se apagam as informações ao longo do tempo de uso da peça, prejudicando as condições de cuidado pelo usuário.

As etiquetas feitas a partir de materiais como algodão, por exemplo, elevam, em certa medida, os custos de confecção, embora sejam mais confortáveis ao toque em comparação as fabricadas em nylon.

Assim, deve-se medir quais os benefícios entre um preço mais baixo no produto final ou a satisfação do consumidor em sua experiência com a marca.

\subsection{Etiqueta institucional}

As etiquetas institucionais podem ser confeccionadas por diferentes materiais ou técnicas de impressão. Já que são as etiquetas que levam o nome da marca, ganham infinitas possibilidades de matérias primas de acordo com a proposta visual de sua identidade.

Dessa forma, tais etiquetas podem ser confeccionadas por etiquetas de algodão, bordadas ou impressas, de metal costuradas ao tecido, usando de uma imagem serigrafada impressa diretamente no tecido ou ainda sobre um tecido sobreposto a peça, ou tantos outros métodos de aplicação.

Algumas dessas etiquetas também podem gerar desconforto, principalmente se anexadas internamente nas peças. Seja por um material com relevo muito pronunciado, pela utilização de pequenas peças de metal ou simplesmente pelas bordas pontiagudas causando atrito e incômodo na pele.

\subsection{Etiqueta promocional ou tag}

Os materiais mais utilizados na fabricação das etiquetas promocionais ou tags são o papelão ou substrato plástico, presos de diferentes formas, seja por laços, lacres, fitas incluindo sempre o logotipo da marca. Como essas etiquetas não acompanham o usuário durante a vida útil do produto questões de usabilidade não podem ser analisadas. No entanto, são capazes de interagir com os consumidores por meio de aspectos simbólicos na relação complexa vivenciada pelos indivíduos na escolha pelo vestuário.

Ante o exposto, salientamos que é tarefa dos designers propor novos materiais que estejam alinhados com as necessidades dos usuários, tanto no que se refere aos parâmetros de usabilidade e de conforto, gerando condições favoráveis para a utilização prolongada da interface/etiqueta, tanto para os aspectos visuais que compõem seu design. Nesse sentido, acompanhar as inclinações do mercado e o posicionamento dos consumidores conduz ao entendimento mais completo sobre o projeto. 
A seguir apresentam-se alguns insights que relacionam as tendências ao universo das etiquetas e tags.

\section{Tendências para etiquetas e tags}

A maioria das tendências em etiquetas e tags está relacionada com as tendências direcionadas ao vestuário. Uma das principais visões para o futuro desses artigos são as cores. Grandes especialistas investigam em feiras, estúdios de prospecção, no comportamento de pessoas influentes, pistas que identifiquem as cores predominantes nas cartelas dos próximos dois anos. Ou em outros termos: as cores da estação.

A cor é um elemento de grande impacto visual e por isso, determinante na escolha da composição do layout de uma etiqueta e/ou tag. As cores são estabelecidas por estímulos psicológicos em relação a sensibilidade humana, capazes de influenciar nossas preferências e decidir pela compra de um produto em detrimento de outro (FARINA, et al., 2011).

Um bom exemplo no mercado brasileiro é a já citada empresa catarinense, Tecnoblu, com sede em Blumenau. $\mathrm{O}$ começo de sua trajetória se deu a mais de vinte anos, construindo seu diferencial através da prospecção de tendências e comportamentos para gerar produtos inovadores e alinhados com o zeitgaist (espírito do tempo). Desde 2007, a empresa conta com um estúdio criativo, um espaço de inteligência da marca na concepção de books de tendências. 0 estúdio possui times de desenvolvimento especializados em mercados distintos, que são responsáveis pela construção dos books apresentados continuamente, a cada nova estação para os diferentes estilos e segmentos trabalhados pela empresa. Investir em planejamento visual, em personalização por meio dessas visões de futuro, transcritas em elementos visuais, é estar em consonância com o mercado e com as necessidades dos consumidores (MANTHEY, 2014).

O book torna-se a principal ferramenta de vendas para os representantes da marca, que carregam não só os produtos, mas um trabalho complexo de investigação de tendências em cores, formas, materiais e assim, confluências de comportamentos de consumo. O último preview compartilhou um pouco da atmosfera chamada de blooming spring \& summer 19 que capta as sensações e influências para este ano. A Figura 5 e 6 trazem algumas imagens que fazem parte do acervo de referências desse ensaio. 
Figura 5 - Tendências para etiquetas 2019.
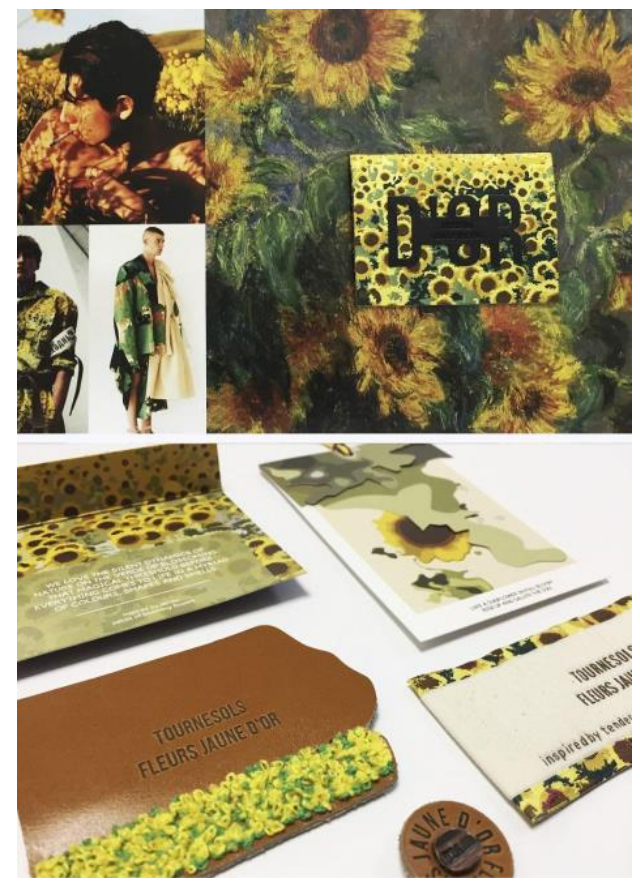

Fonte: abit.org.br (2017)

Figura 6 - Tendências para etiquetas 2019.
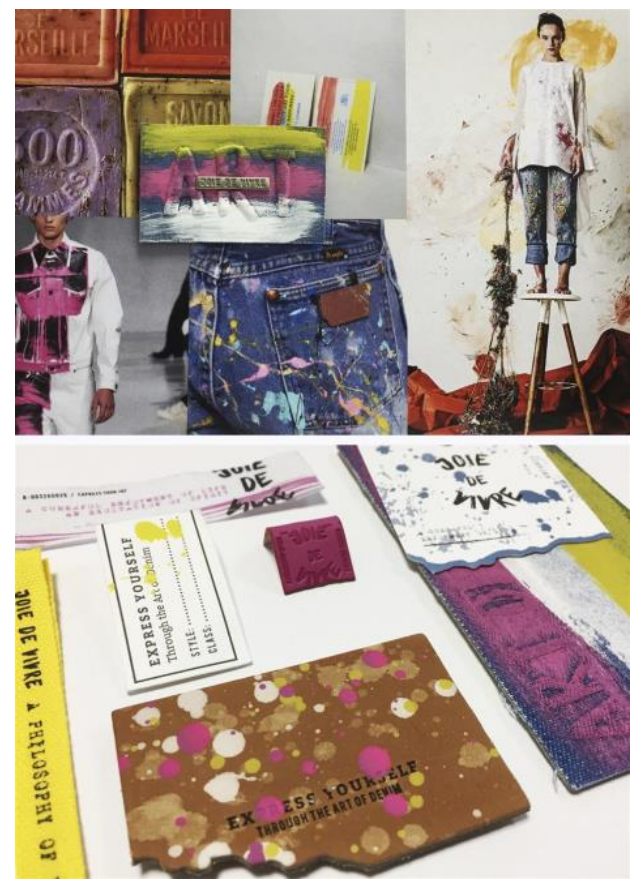

Fonte: abit.org.br (2017)

Assim como tendências se direcionam ao vestuário, o mesmo acontece com as etiquetas e tags. Os sinais são geralmente muito similares, já que estamos falando de um complemento aos produtos têxteis, mas que não devem ser ignorados na concepção dessas interfaces. O importante é estar atento a essas mudanças e absorvê-las conforme as especificidades de seu público e sua 
identidade como marca.

Há uma série de materiais a serem explorados na concepção de etiquetas, sejam tecidos de diferentes origens e gramaturas, papéis de diferentes texturas e acabamentos, superfícies emborrachadas, relevos metalizados, bordados e diferentes entrelaçamentos de fios, aplicações de aviamentos, sobreposições de camadas de substratos diferentes. E ainda combinações entre materiais gerando novas oportunidades de construção.

\section{Considerações finais}

O objetivo desse ensaio compreendeu descrever os principais tipos de etiquetas concebidas para o vestuário e suas interações com os usuários através de seus elementos visuais e suas funções comunicacionais. Em um primeiro momento, a categorização dos diferentes tipos de etiquetas foi explanada, assim como suas correspondentes atribuições de relação com o usuário e seus elementos gráficos de destaque. Na sequência, identificamos os materiais mais utilizados na concepção das etiquetas e enfatizamos a importância de sua escolha em favor de requisitos básicos de usabilidade, como o conforto e a apresentação adequada das informações nessas interfaces. Assim, compreendidos os aspectos formais na elaboração das etiquetas, iniciamos a discussão de um olhar mais atento para as tendências neste universo, caracterizado como sendo um complemento dos produtos têxteis.

O enfoque de todo este estudo é conduzir a uma percepção mais atenta dos profissionais de criação dessas interfaces na interação dos usuários com esses artigos. A eficiência no design passa por diversos âmbitos que impactam o comportamento dos indivíduos diante de seus produtos ou interfaces, principalmente em relação aos aspectos simbólicos que afetam o entendimento sobre o objeto de análise.

Estar atento a questões de usabilidade também faz parte do papel do designer no desenvolvimento das etiquetas e tags. A maioria dessas interfaces está em contato direto com o corpo, sendo capazes de gerar desconforto durante o uso das peças de vestuário, fazendo com que muitos usuários retirem suas etiquetas diante desse incômodo. Em razão deste fato, informações são perdidas, ocasionando o desconhecimento pelos usuários de como cuidar de suas peças nos processos que concernem a manutenção do produto como lavagem, secagem e passadoria. Além de muitas outras informações essenciais, como a composição dos tecidos, tamanho das peças e, no caso das etiquetas informacionais a perda da grafia correspondente ao nome das marcas.

A pesquisa apresenta relevância acadêmica e profissional, já que contribui para o estudo da comunicação de interfaces têxteis, que representam um importante item na construção dos produtos de vestuário e na apresentação das marcas diante de seus clientes. Poucos estudos se debruçaram sobre este tema, em específico na elucidação dos materiais e tendências utilizadas no segmento.

Como sugestão a pesquisas futuras, a investigação de novos nichos de mercado para atender necessidades de interação com as etiquetas por públicos com deficiência ou com algum tipo de dificuldade no entendimento das informações do vestuário. Guiado sempre com o objetivo de aperfeiçoar a relação entre usuário e interface. 


\section{Referências}

ASSOCIAÇÃO BRASILEIRA DE NORMAS TÉCNICAS - ABNT. NBR NM ISSO 3758. Têxteis: códigos de cuidado usando símbolos, Rio de Janeiro, 2013.

FARINA, M.; PEREZ, C.; BASTOS, D. Psicodinâmica das cores em comunicação. São Paulo: Blucher, 2011.

GARCIA, L. J.; FERNANDES, C. A.; MERINO, E. A. D.; BRAVIANO, G. Usabilidade: a experiência do usuário com etiquetas de roupas. In: Anais II Conferência Internacional de Design, Engenharia e Gestão para a inovação - IDEMI, Florianópolis, 2012.

LURIE, A. A linguagem das roupas. Rio de Janeiro: Rocco, 1997.

MACKENZIE, M. Ismos: para entender a moda. São Paulo: Globo, 2010.

MANTHEY, B. N.; MARINHO, V. S.; ALBERTON, A. Da etiqueta ao desejo: o caso Tecnoblu. Revista Pensamento Contemporâneo em Administração. Rio de Janeiro, v.8, n.4, p.163-180, 2014.

SCHNEIDER, J. Elaboração de requisitos para o aperfeiçoamento do projeto de etiquetas técnicas de manutenção e conservação têxtil: um estudo fundamentado na ergonomia e na usabilidade. 2016. Dissertação (Mestrado em Design) - Universidade do Estado de Santa Catarina - UDESC, Florianópolis, 2016.

SIROTTI, G. The world of fashion labels and tags: thematic guide of the ultimate graphic collection. Modena: Happy Books, 2000.

SVENDSEN, L. Moda, uma filosofia. Editora: Zahar. Rio de Janeiro, 2010. 